\title{
PROPENSÃO EMPREENDEDORA ENTRE ESTUDANTES PARTICIPANTES DE EMPRESAS JUNIORES
}

\author{
Emanoel Renato Andrade Ferreira - Universidade Estadual do Ceará ${ }^{1}$ \\ Ana Augusta Ferreira de Freitas - Universidade Estadual do Ceará
}

Resumo: O propósito deste estudo é identificar se a participação em atividades das Empresas Juniores contribui para a propensão empreendedora dos alunos que a compõem, por meio do desenvolvimento de características comportamentais associadas ao empreendedorismo. Utilizou-se a metodologia survey para este estudo. Fizeram parte da amostra 88 graduandos que não participam de Empresa Júnior e 75 que participam ou participaram. Quando comparados os dois grupos, os achados indicam que os alunos de Empresa Júnior apresentam cinco médias significativamente superiores em itens de comportamento empreendedor. Além disto, há maior propensão entre os alunos de Empresa Júnior a abrirem uma empresa, em prazos mais longos, quando comparados ao que não participaram desta atividade. É possível sugerir que a experiência em Empresa Júnior influencia a propensão empreendedora dos estudantes, através do desenvolvimento de atitudes empreendedoras e do interesse em iniciar um novo negócio.

Palavras-chave: Empreendedorismo; Educação Empreendedora; Propensão Empreendedora; Empresa Júnior; Atitudes Empreendedoras.

\section{ENTREPRENEURIAL PROPENSITY'S STUDENTS PARTICIPATING ON JUNIOR ENTERPRISE}

\begin{abstract}
The purpose of this study is to identify whether Junior Enterprise Associations, a professional like gathering of undergraduate students in Business Administration to provide consulting services, contribute to the entrepreneurial propensity of their components. Through a descriptive study, 163 undergraduate students in Business Administration were surveyed, with 88 undergraduates who had not participated in Junior Enterprises and 75 who participated or are participating. Findings indicate that the latter presented 5 higher significant mean behaviors when compared with students who did not participate. It was also observed a greater propensity of students of Junior Enterprise to start a business of their own in the long term as compared to their non-participant counterparts. It is possible to suggest that working experience in a Junior Enterprise Association environment influence the likelihood of students in developing entrepreneurial attitudes and actually engaging in a start up business activity.
\end{abstract}

Keywords: Empreendedorismo; Educação Empreendedora; Propensão Empreendedora; Empresa Júnior; Atitudes Empreendedoras.

\footnotetext{
${ }^{1}$ E.mail: emanoelrenato.adm@gmail.com. Endereço: Av. da Universidade 2853 , Benfica, Fortaleza - CE - CEP: 600020-181.

2 E.mail: freitas8@terra.com.br
}

FERREIRA, E. R. A.; FREITAS, A. A. F. Propensão empreendedora entre estudantes participantes de empresas juniores. Revista de Empreendedorismo e 


\section{Introdução}

A lógica de desenvolvimento promovida pelo empreendedorismo, e comumente comunicada consiste na ideia de que, ao abrir um negócio, este tenderá a geração de empregos, maior competitividade no ambiente de mercado, desenvolvimento de melhores formas de produzir, bem como possibilidades de inovação. Essas resultantes convergem para o desenvolvimento econômico local, regional ou nacional. Apesar da lógica de desenvolvimento econômico a partir do empreendedorismo envolver maior complexidade, o processo formal de abertura de empresas sob a justificativa da exploração de uma oportunidade possui impacto relevante na economia (ÀCS, 2007).

Desta forma, torna-se importante que os países objetivem criar mecanismos que incentivem a propensão empreendedora deliberada (por opção de exploração de uma oportunidade e não por pressão econômica e/ou social) (ÀCS, 2007; GEM, 2007), por meio da criação de leis de incentivo ao empreendedor, da diminuição de barreiras para a formalização das empresas e da criação de programas de educação empreendedora em Instituições de Ensino, por exemplo.

Em relação às últimas, os programas de educação empreendedora têm por propósito primário incentivar a consciência e a propensão empreendedora, bem como o desenvolvimento de competências chaves do comportamento empreendedor (EUROPEAN COMISSION, 2012). Alguns destes possuem em seus currículos o desenvolvimento de planos de negócios e a exposição de estudos de casos, enquanto outros vinculam suas atividades à prática do empreendedorismo, o que possibilita aos estudantes tornarem-se mais criativos, autoconfiantes e conscientes do seu papel na sociedade.

As Empresas Juniores são exemplos de programas de educação empreendedora vinculadas a Instituições de Ensino Superior (IES). Essas empresas são concebidas como organizações sem fins lucrativos formadas por estudantes de graduação com a finalidade de aliar à teoria a prática (BATISTA et al., 2010; BRASIL JÚNIOR, 2008; FRANCO; FEITOSA, 2006). Nessas organizações, os alunos podem ter a experiência de gerenciar uma empresa, antes de sair da IES, o que, segundo 
estudos prévios, é um mecanismo de aprendizado, por meio da prática, que contribui para o desenvolvimento de competências e para formação de profissionais diferenciados (EUROPEAN COMISSION, 2012; VALADÃO JÚNIOR; MARQUES, 2012; BATISTA et al., 2010; VAZQUEZ, 2012; DAL PIVA et al.,2006; FRANCO; FEITOSA, 2006).

Até então, observa-se pelos estudos realizados que a Empresa Júnior cria um ambiente propício, por meio de suas atividades, para o desenvolvimento competências que contribuem para a formação profissional de universitários. Contudo, ainda é desconhecido se a participação em Empresas Juniores contribui para uma maior propensão empreendedora de seus componentes, quando comparados com estudantes que não participam desta experiência, o que, de acordo com a Confederação Brasileira de Empresas Juniores - Brasil Júnior - (2009), é um dos seus objetivos de existência.

Desta forma, o presente estudo tem o propósito de identificar se a participação em atividades das Empresas Juniores contribuem para a propensão empreendedora dos alunos que a compõem, por meio do desenvolvimento de características comportamentais associadas ao empreendedorismo. Para tanto, será aplicada uma pesquisa com dois grupos de graduandos, sendo um grupo composto por alunos que se encontram ou passaram pela experiência em uma Empresa Júnior, e outro grupo de graduandos que não passaram pela mesma experiência. Os achados dos dois grupos serão confrontados, possibilitando a geração de inferências.

\section{Esteio Teórico}

A presente seção irá ser estruturada a partir da articulação teórica entre os autores que estabelecem os pilares do estudo do empreendedorismo e seu agente empreendedor e a educação empreendedora. 


\section{Os pilares do estudo do empreendedorismo e o agente empreendedor}

Embora haja a influência de diversas disciplinas no estudo do empreendedorismo, destacam-se duas relevantes correntes do pensamento empreendedor compostas, de um lado, pelos (I) economistas e, do outro, pelos (II) comportamentalistas. Este último grupo é representado principalmente por Mccleland, Collins e Moore e possui como objeto de estudo o empreendedor como indivíduo, seus comportamentos e motivações (FILION, 1999; STEVENSON; JARILLO, 1990). Já a corrente representada pelos economistas apresenta como objeto de estudo os resultados e impactos da ação empreendedora no contexto econômico (STEVENSON; JARILLO, 1990) e pode ser dividida em dois momentos: a clássica e a neoclássica (MURPHY; LIAO; WELSCH, 2006).

Os economistas Cantillon e, posteriormente, Say contribuíram para constituição da base da abordagem econômica clássica do empreendedorismo, associando o empreendedor as ideias de risco, oportunidade, mudança e inovação (CARMO; NASSIF; 2005). Contudo, foi Joseph Schumpeter, o precursor da corrente empreendedora neoclássica, que mais claramente associou 0 termo empreendedorismo à inovação, esclarecendo a relevância do papel do empreendedor na revitalização da economia, no desequilíbrio da ordem de mercado - destruição criativa - e no desenvolvimento econômico (FILION, 2011; 1997; BYGRAVE, 2003; STEVENSON, JARILLO, 1990).

Os economistas contribuíram significantemente para os estudos sobre empreendedorismo. Contudo, aprofundaram-se na função do empreendedor no contexto econômico, deixando relevantes questionamentos sobre os comportamentos do indivíduo empreendedor. Alguns destes questionamentos só foram respondidos (ou obtiveram conjecturas) com os estudos iniciados por David Mcclelland, precursor da corrente comportamentalista dos estudos sobre empreendedorismo.

O ponto de partida dos comportamentalistas era o questionamento: "quem é o empreendedor?" (FILION, 2000, p. 18). Mccleland foi o primeiro a apresentar um estudo empírico sobre o comportamento empreendedor, demonstrando que os empreendedores possuem uma alta necessidade de realização e de controle 
(DANTAS, 2008; CORNELIUS et al., 2006; BYGRAVE, 2003). Esta inferência pôde ser melhor compreendida em seu livro The Achieving Society, no qual Mccleland discorre sobre os modelos que diferenciam o desenvolvimento de uma sociedade para outra, a partir da influência cultural e da necessidade de realização (CORNELIUS et al., 2006; BYGRAVE, 2003).

Esses estudos são reflexos do reconhecimento da relevância do empreendedor para a sociedade e constituíram a base do empreendedorismo, incentivando o desenvolvimento de novas pesquisas em torno do assunto. Apesar da influência cultural no comportamento do empreendedor e a falta de um perfil psicológico, parece haver certo consenso entre os pesquisadores sobre a existência de características que criam propensão ao empreendedorismo e que estas podem ser desenvolvidas.

À medida que ocorrem avanços no estudo sobre o comportamento empreendedor, paradoxalmente, tem se tornado cada vez mais difícil definir as características do perfil deste agente. Tal fato ocorre em decorrência da quantidade de novas características emergentes a cada estudo acerca deste assunto. Por outro lado, observa-se uma tendência ao aparecimento de características "de natureza mais objetiva do que subjetiva, mais profissional do que amadora (...) e menor peso para fatores como a sorte e os fatores emocionais" (FILARDI et al., 2011, p. 14).

De acordo com um recente estudo realizado por Filardi et al. (2011), no qual foram selecionados e analisados noventa e cinco artigos científicos, de diferentes autores, publicados em periódicos nacionais e internacionais, no período de 1983 a 2010, foram identificadas cento e vinte duas diferentes atitudes do empreendedor, sendo definidas como significativas para a composição do estudo apenas as vinte e sete atitudes mais citadas. Neste caso, observou-se uma maior (frequência) de citação para as seguintes características do empreendedor contemporâneo: próatividade, inovação, tolerância a risco, criatividade, liderança, visão, ambição, relacionamento interpessoal, flexibilidade e, por fim, perseverança.

A evolução dos estudos sobre o empreendedorismo, não apenas contribuiu com a expansão do número de características do empreendedor (FILARDI et al., 2011), como também com o surgimento de diferentes definições e categorias para o empreendedorismo. Sobre este assunto, Filion (2011, p.7) acrescenta que "não é 
possível definir o empreendedor somente a partir das características deles (...) as características são utilizadas para refinar e deixar claro certos aspectos da definição, mas não para reconhecer o seu todo".

O mesmo autor ainda sugere a utilização de seis elementos essenciais, com foco na ação empreendedora, para a formação da definição de empreendedorismo: inovação, reconhecimento de oportunidades, ação, gestão de risco, uso de recursos e valor acrescentado. Apesar da diversidade de definições, o empreendedorismo, em síntese, é associado a uma ação proveniente da percepção de uma oportunidade que resulta na abertura de um negócio (GEM, 2002; HOJJATI, 2012; BYGRAVE, 2008; BAUMOL, 1993) ou na introdução de produtos inovadores (BAUMOL, 1993), a partir da descoberta, avaliação e aproveitamento de oportunidades (STEVENSON; JARILLO, 1990).

Nesta linha, um estudo desenvolvido por Schmidt e Bohnenberger (2009), com o propósito de desenvolver um instrumento de pesquisa que verificasse 0 impacto do perfil empreendedor no desempenho das organizações, identificou seis construtos inerentes ao comportamento empreendedor: (I) Auto-realização; (II) Líder; (III) Assume riscos; (IV) Planejador; (V) Inovador; e (VI) Sociável. A partir destes seis construtos, os autores supracitados desenvolveram uma escala que embasará a parte empírica do presente estudo.

O estudo do empreendedorismo tem tomado maiores proporções nas últimas décadas em decorrência do reconhecimento do papel do empreendedor e os seus impactos na economia, bem como os fatores que influenciam a propensão ao empreendedorismo (BYGRAVE, 2003). Nota-se a difusão do assunto pelo número de cursos em IES e o aumento de organizações que promovem 0 empreendedorismo, por meio de programas de educação empreendedora. Este contexto revela uma questão: o empreendedorismo pode ser ensinado?

\section{A educação empreendedora e as atividades educacionais, com ênfase nas}

\section{Empresas Juniores}

O primeiro passo para entender a importância dos programas de educação empreendedora é compreender se o empreendedorismo pode ser ensinado. De 
acordo com Kuratko (2005; 2006), este é um questionamento "obsoleto". Há estudiosos que defendem que o empreendedorismo trará maiores resultados quando ensinado ainda no ensino secundário (CHEUNG, 2012; RAMAYAH; AHMAD; FEI, 2012) e até mesmo no primário (RAMAYAH et al.,2012), sendo uma oportunidade prévia de incentivar o desenvolvimento de comportamentos e capacidades empreendedoras.

A educação empreendedora tem como propósito preparar empreendedores e potenciais empreendedores com capacidades para enfrentar os desafios de abertura, sustentabilidade e crescimento dos empreendimentos no ambiente de mercado (ELMUTI et al., 2012; BAGHERI; PIHIE, 2009; SAES; PITA, 2007). Além de objetivar a criação de propensão ao empreendedorismo nos participantes, estes programas de educação também têm como propósito criar o ambiente propício para o desenvolvimento das capacidades e comportamentos, os quais irão ajudar os estudantes não só como potenciais empreendedores, mas como "futuro profissional em qualquer organização" (RAMAYAH; AHMAD; FEI, 2012, p.78).

O ensino do empreendedorismo tem sido alvo de discussões sobre "o que" e "como" ensinar efetivamente e fomentar o desenvolvimento de capacidades e habilidades empreendedoras, bem como a apreensão de conhecimentos (KURATKO, 2006). Elmuti et al. (2012), a partir de um levantamento sobre programas de educação empreendedora em nove instituições de ensino superior (IES) de quatro países, apontaram que a exploração de oportunidades de mercado, A viabilidade de negócios, O plano de negócios e a inovação são conteúdos que a maioria das IES possuem em seus currículos.

Por outro lado, a discussão principal está voltada para os métodos de ensino que devem ir além da exposição de teorias e técnicas de como criar planos de negócios, analisar oportunidades ambientais, inovar, e realizar exames. Em revisão de estudos recentes (e.g. ELMUTI et al., 2012; BARGHERI; PIHIE, 2009; SAES; PITA, 2007) encontram-se resultados que indicam a necessidade de um ensino voltado para a prática, por meio da inclusão de casos reais, interação e reflexão em grupo, saindo do típico ensino voltado para a conversa de mão única - o discurso do professor para o aluno. 
E neste sentido, se percebe que o ensino do empreendedorismo deve ser entendido como uma forma de aprendizado, por meio da interação entre estudantes, prática e análise de casos reais (ELMUTI et al. 2012; CHEUNG; FEI, 2012; SAES; PITA, 2007). Um estudo realizado por Cheung et al. (2012) sobre educação empreendedora demonstrou que a experiência de gestão de um pequeno negócio dentro de uma instituição de ensino, em Hong Kong, aumentou o número de interessados em tornarem-se empreendedores. Outro achado desta mesma pesquisa apresentou que, após a vivência prática, a possibilidade de empreender foi fortalecida como uma alternativa de trabalho, caso os participantes viessem a estar desempregados no futuro.

Em outra pesquisa realizada por Ramayah et al. (2012), os autores mostraram os resultado do impacto da experiência prévia no comportamento empreendedor de estudantes universitários. Um primeiro achado significativo indicou que os estudantes que não tiveram envolvimento com programas de educação empreendedora tendiam a ter uma percepção de obstáculos maior do que aqueles que já tiveram algum envolvimento com educação empreendedora. Por outro lado, jovens estudantes que já tiveram alguma experiência empreendedora prévia e que participaram de cursos ou treinamentos sobre empreendedorismo apresentaram um maior aprimoramento de todas as demais características empreendedoras em estudo (RAMAYAH; AHMAD; FEI, 2012).

Dentro deste contexto, se percebe que instituição de ensino superior é uma grande aliada no incentivo ao desenvolvimento e aprimoramento das características empreendedoras, por meio das oportunidades que o ambiente universitário proporciona: aprendizado experimental, aprendizado a partir da interação social e o reconhecimento de oportunidades de negócios (BAGHERI; PIHIE, 2009). Destacase dos três aspectos anteriores, a interação social e o seu papel na formação e aprimoramento do comportamento empreendedor a partir da troca de conhecimentos e experiências, criação e reconhecimento de oportunidades (BAGHERI; PIHIE, 2009).

Entendendo a importância da vivência prática do empreendedorismo como uma alternativa de ensino envolvente e a importância da teoria como fator orientador da tomada de decisão, Ramayah et al. (2012, p. 14) afirmam que "os objetivos do 
ensino do empreendedorismo seriam melhor alcançados se a teoria e a prática fossem incentivadas ao mesmo tempo nas Universidades".

Superada as discussões de como o empreendedorismo poderá ser ensinado, outro questionamento vem à tona: como mensurar a eficácia dos programas de educação empreendedora? Um dos principais indicadores utilizados na mensuração da eficácia desses programas é o número de planos de negócios elaborados. Entretanto, este indicador sozinho não dá suporte para a avaliação de efetividade do programa, fazendo com que sejam necessários outros indicadores. Boyles (2012) sugere que a mensuração dos programas de educação empreendedora poderá ser mais eficaz com a inclusão de mecanismos de avaliação de competências do século XXI e competências empreendedoras.

A importância do desenvolvimento de competências na formação de futuros empreendedores tem sido expressa pela demanda de capital humano preparado, por parte das empresas, e pela a quantidade de estudos científicos abordando esta temática. Boyles (2012), por sua vez, apresenta um interessante modelo de avaliação de resultados, para os programas de educação empreendedora, focalizado no desenvolvimento de competências fundamentais para a formação de um empreendedor de sucesso. As competências em foco são: resolução de problemas complexos, criatividade/pensamento inovador, trabalho em equipe e colaboração, planejamento e execução, adaptabilidade, autonomia e capacidades de comunicação (escrita e oral).

O método de ensino orientado para o alinhamento entre a teoria e a prática são fatores preponderantes para a formação de empreendedores. Aliada ao método de ensino existe a mensuração da eficácia destes programas de educação empreendedora que tem sido reorientada para a utilização de fatores comportamentais como crivos de sucesso do programa. Assim, compreendendo os desafios da educação empreendedora e a importância do desenvolvimento de comportamentos empreendedores e da aliança entre a teoria e a prática consistente na vivência de gestão de um negócio, apresenta-se um modelo utilizado em diversas IES brasileiras denominado de Empresa Júnior.

A Empresa Júnior (EJ) é uma associação sem fins econômicos gerenciada e formada única e exclusivamente por graduandos de um ou mais cursos superiores 
que prestam serviços de consultoria e realizam projetos a preço de custo (BRASIL JÚNIOR, 2008). Por meio da prestação de serviços relacionados aos seus cursos de graduação para clientes, os estudantes podem aliar a teoria à prática, obtendo um desenvolvimento profissional diferenciado, o que torna esta experiência "um aprendizado significativo para a formação dos alunos" (VAZQUEZ et al., 2012, pág. 14).

Este mecanismo pedagógico que incentiva a vivência prática dos conhecimentos assimilados em sala de aula teve início na França, em 1967, por meio da criação da Júnior-Enterprise da ESSEC (L'Ecole Supérieure des Sciences Economiques et Commerciales de Paris), caracterizada como uma forma de complementar os estudos dos graduandos a partir da prática da realidade empresarial, ainda dentro da Instituição de Ensino Superior. Após a difusão do Movimento Empresa Júnior pela Europa, em 1987, o conceito chega ao Brasil, através da Câmara de Comércio Franco-Brasileira, e, em 1989, é criada a primeira Empresa Júnior do Brasil: Júnior GV da Escola de Administração de Empresas da Fundação Getúlio Vargas (BRASIL JÚNIOR, 2008).

De acordo com a Confederação Brasileira de Empresas Juniores - Brasil Júnior - instância representativa do Movimento Empresa Júnior no Brasil, estima-se que existam "1120 Empresas e 27800 empresários juniores", entre confederados apresentam os requisitos mínimos para serem regulamentados pela Brasil Júnior - e não confederados em nosso país (BRASIL JÚNIOR, 2011). Em um estudo realizado, em 2012, com 365 Empresas Juniores, foi identificado que o faturamento médio das EJs é de $R \$ 23.705,23$, resultando em um PIB de $R \$ 8.652 .407,92$ no ano de 2011 (BRASIL JÚNIOR, 2012). Outro achado significativo deste mesmo levantamento aponta que foram realizados 2216 projetos para clientes, sendo 6,07 projetos, em média, de consultoria por EJ.

As receitas provenientes da realização desses projetos devem ser reinvestidas na própria Empresa Júnior, não podendo haver a distribuição de valores financeiros entre os seus membros no formato de salário, mas apenas para reembolso de despesas, o que caracteriza um estímulo à prática de responsabilidade social corporativa, por meio do voluntariado ainda dentro da IES (BRASIL JÚNIOR, 2008). Esta característica contribui para um preço abaixo de 
mercado, possibilitando micro e pequenos empreendedores terem acesso à serviços de consultoria, os quais são orientados por professores dessas Instituições de Ensino Superior.

A gestão das EJs é realizada pelos acadêmicos que as compõem, portanto, havendo certo nível de autonomia frente ao corpo docente e coordenadores da IES, o que torna esses componentes responsáveis pelos atos da EJ (BRASIL JÚNIOR, 2008). Porém, ressalta-se a importância da presença docente a fim de orientar as atividades realizadas pelos graduandos e contribuir com a criação de um ambiente propício para o aprendizado a partir desta experiência (VAZQUEZ et al., 2012; DAL PIVA et al., 2006).

As Empresas Juniores, portanto, devem ser vinculadas a, pelo menos, uma Instituição de Ensino Superior, não podendo ter posicionamento político (BRASIL JÚNIOR, 2008; 2009). De acordo com o documento intitulado Conceito Nacional de Empresa Júnior, o qual tem como finalidade definir critérios a serem seguidos para a configuração de uma associação civil como a Empresa Júnior, foram destacados três propósitos que deverão estar presentes no estatuto de uma EJ:

I. Desenvolver profissionalmente as pessoas que compõem o quadro social por meio da vivência empresarial, realizando projetos e serviços na área de atuação do(s) curso(s) de graduação ao(s) qual (is) a empresa júnior for vinculada;

II. Realizar projetos e/ou serviços preferencialmente para micro e pequenas empresas, e terceiro setor, nacionais, em funcionamento ou em fase de abertura, ou pessoas físicas, visando ao desenvolvimento da sociedade;

III. Fomentar o empreendedorismo de seus associados (BRASIL JÚNIOR, p. 1, 2009)

A partir deste documento e de outras referências percebe-se ainda que o objetivo precípuo e uma EJ é criar um ambiente propício para o aprendizado e formação de futuros profissionais a partir:da interação social e cooperação entre membros (VAZQUEZ et al., 2012; BATISTA et al., 2010); da realização de projetos para clientes e do estudo prévio de conhecimentos específicos para as consultorias a serem realizadas (FRANCO; FEITOSA, 2008); da realização de projetos internos que são voltados para a gestão da própria empresa (BATISTA et al., 2010); da 
responsabilidade em assumir cargos de direção (LEMOS, et al., 2012); do fomento ao empreendedorismo (BRASIL JÚNIOR, 2009); e da realização de atividades rotineiras - processos - da Empresa Júnior. Estas experiências formam o principal fator motivacional para o engajamento de graduandos em Empresas Juniores, qual seja, o aprendizado (BRASIL JÚNIOR, 2012; SOUZA et al., 2008).

Sobre o assunto, em um recente estudo realizado por Valadão Júnior e Marques (2012) foram identificadas competências desenvolvidas em egressos de uma Empresa Júnior e a importância desta na formação do graduando por meio de depoimentos. Dentre as competências mais representativas estão: (I) Metacompetências e Transcompetências: habilidades de comunicação; (II) Competências Cognitivas: capacidade de mobilizar e transpor conhecimentos; conhecimentos técnicos em Administração; (III) Competências Funcionais: habilidade de liderança; atendimento/negociação; (IV) Competências Comportamentais:capacidade de trabalhar em equipe; relacionamento interpessoal. Outro achado significativo desta pesquisa aponta algumas limitações da experiência, entre elas: a alta rotatividade; a oscilação na demanda de projetos externos; as limitações de recursos; a imaturidade dos alunos; e a falta de divulgação dos trabalhos da empresa (VALADÃO JÚNIOR; MARQUES, 2012).

Entendida a percepção dos egressos sobre essa experiência na pesquisa supracitada, outro estudo, sendo este desenvolvido por Lemos et al. (2012), buscou identificar quais são os valores dos jovens acadêmicos que integram uma Empresa Júnior. Por meio de 45 entrevistas com membros de EJs do Rio de Janeiro, observou-se que estes jovens apresentam: necessidade de auto-realização e sucesso; auto-suficiência caracterizada pela autonomia em ações; necessidade de estímulos que caracteriza os jovens como: "ansiosos por novidades, desafios e pouco tolerantes ao cotidiano e procedimentos sempre iguais e rotineiros" (LEMOS, et al. 2012, p. 99); necessidade de poder caracterizada pelo desejo de influenciar pessoas; e o sentimento de prazer e auto-gratificação gerados por esta experiência. Portanto, é possível sugerir que estes jovens são "indivíduos arrojados, independentes e propensos a correr riscos, desejosos de poder e realização profissional” (LEMOS et al., 2012, p. 102). 
Por outro lado, Ferreira et al. (2009) corrobora que a participação em Empresa Júnior contribui para a diferenciação profissional dos seus participantes e acrescenta que esta experiência tende a ser mais valorizada pelos egressos que apresentam características empreendedoras. Este estudo foi realizado com 44 pósjuniores de uma EJ de Economia de Portugal e, por meio de um questionário, foi identificado que apenas 50\% deles apresentavam propensão a empreender (tinham características empreendedoras) e outro achado apresentou que apenas 4 pesquisados iniciaram a sua carreira com um próprio negócio e que, no período de finalização do estudo (2009), apenas 3 estavam gerindo o próprio negócio. Contudo, por meio do teste Hosmer and Lameshow, concluiu-se que a experiência na EJ em questão contribuía sim para o desenvolvimento de características empreendedoras.

Por fim, pode-se afirmar que a experiência de gestão de um negócio e a interação social, com clientes, professores e outros alunos, os riscos que os alunos assumem e o conhecimento adquirido ao elaborar uma proposta de projeto, negociar com o cliente e ao executar um projeto de consultoria, são fatores preponderantes para a formação de um profissional diferenciado (BATISTA et al., 2010; FRANCO; FEITOSA, 2008; DAL PIVA et al., 2006) com propensões para liderar e empreender (VALADÃO JÚNIOR; MARQUES, 2012; DAL PIVA et al., 2006). Há também o aumento das oportunidades de empregabilidade, resultante do desenvolvimento de características profissionais provenientes da experiência prévia de condução de um negócio (DAL PIVA et al., 2006).

\section{Metodologia}

A fundamentação teórica desenvolvida sobre empreendedorismo e empreendedores, educação empreendedora e Movimento Empresa Júnior, por meio de levantamento bibliográfico, teve por objetivo uma maior compreensão sobre o problema do presente estudo: a experiência em Empresas Juniores contribui para a criação de propensão empreendedora em seus participantes?

Para responder este questionamento, foi realizada uma pesquisa de caráter descritivo. A pesquisa descritiva tem por propósito descrever o objeto de pesquisa, pressupondo a existência de informações prévias significativas que possibilitam a 
realização de um estudo mais específico sobre o comportamento da situaçãoproblema (MALHOTRA, 2006). A pesquisa descritiva deste estudo é classificada como transversal, pois foi extraída uma amostra pesquisada apenas uma vez (MALHOTRA, 2006).

Utilizou-se a metodologia survey para este estudo. No questionário concebido para o estudo foi utilizada uma escala para mensuração do perfil empreendedor, que teve por base o trabalho de Schmidt e Bohnenberger (2009). Esta escala é composta por itens de medição que caracterizam a manifestação dos construtos relacionados ao comportamento empreendedor, quais sejam: autorealização, líder, planejador, inovador, assume riscos e sociável (Quadro 1). Os itens da escala foram avaliados por meio de uma escala Likert de sete pontos que variava do discordo plenamente (1) até o concordo plenamente (7). 
Quadro 1: Fatores e variáveis da escala de mensuração da propensão empreendedora.

\begin{tabular}{|c|c|}
\hline FATORES & VARIÁVEIS \\
\hline \multirow{5}{*}{$\begin{array}{l}\text { Fator 1- Auto- } \\
\text { realização }\end{array}$} & $\begin{array}{l}\text { Frequentemente detecto oportunidades de negócio no } \\
\text { mercado. }\end{array}$ \\
\hline & $\begin{array}{l}\text { Creio que tenho uma boa habilidade em detectar } \\
\text { oportunidades de negócio no mercado. }\end{array}$ \\
\hline & $\begin{array}{l}\text { Tenho controle sobre os fatores para minha plena } \\
\text { realização profissional. }\end{array}$ \\
\hline & $\begin{array}{l}\text { Profissionalmente, me considero uma pessoa muito } \\
\text { mais persistente que as demais. }\end{array}$ \\
\hline & $\begin{array}{l}\text { Sempre encontro soluções muito criativas para } \\
\text { problemas profissionais com os quais me deparo. }\end{array}$ \\
\hline \multirow{5}{*}{ Fator 2- Líder } & Tenho um bom plano da minha vida profissional. \\
\hline & $\begin{array}{l}\text { Frequentemente sou escolhido como líder em projetos } \\
\text { ou atividades profissionais. }\end{array}$ \\
\hline & $\begin{array}{l}\text { Frequentemente as pessoas pedem minha opinião } \\
\text { sobre assuntos de trabalho. }\end{array}$ \\
\hline & As pessoas respeitam minha opinião. \\
\hline & Me relaciono muito facilmente com outras pessoas. \\
\hline FATORES & VARIÁVEIS \\
\hline \multirow{3}{*}{$\begin{array}{l}\text { Fator } 3 \text { - } \\
\text { Planejador }\end{array}$} & $\begin{array}{l}\text { No meu trabalho, sempre planejo muito bem tudo o } \\
\text { que faço. }\end{array}$ \\
\hline & $\begin{array}{l}\text { Sempre procuro estudar muito a respeito de cada } \\
\text { situação profissional que envolva algum tipo de risco. }\end{array}$ \\
\hline & $\begin{array}{l}\text { Tenho os assuntos referentes ao trabalho sempre } \\
\text { muito bem planejados. }\end{array}$ \\
\hline \multirow{2}{*}{ Fator 4 - Inovador } & $\begin{array}{l}\text { Prefiro um trabalho repleto de novidades a uma } \\
\text { atividade rotineira. }\end{array}$ \\
\hline & $\begin{array}{l}\text { Gosto de mudar minha forma de trabalho sempre que } \\
\text { possível. }\end{array}$ \\
\hline \multirow{4}{*}{$\begin{array}{l}\text { Fator } 5 \text { - Assume } \\
\text { riscos }\end{array}$} & $\begin{array}{l}\text { Me incomoda muito ser pego de surpresa por fatos } \\
\text { que eu poderia ter previsto. }\end{array}$ \\
\hline & $\begin{array}{l}\text { Eu assumiria uma dívida de longo prazo, acreditando } \\
\text { nas vantagens que uma oportunidade de negócio me } \\
\text { traria. }\end{array}$ \\
\hline & $\begin{array}{l}\text { No trabalho, normalmente influencio a opinião de } \\
\text { outras pessoas a respeito de um determinado } \\
\text { assunto. }\end{array}$ \\
\hline & Admito correr riscos em troca de possíveis benefícios. \\
\hline \multirow{3}{*}{ Fator 6 - Sociável } & $\begin{array}{l}\text { Meus contatos sociais influenciam muito pouco a } \\
\text { minha vida profissional. }\end{array}$ \\
\hline & $\begin{array}{l}\text { Os contatos sociais que tenho são muito importantes } \\
\text { para minha vida pessoal. }\end{array}$ \\
\hline & $\begin{array}{l}\text { Conheço várias pessoas que me poderiam auxiliar } \\
\text { profissionalmente, caso eu precisasse. }\end{array}$ \\
\hline
\end{tabular}

Fonte: Schmidt e Bohnenberger, 2009.

FERREIRA, E. R. A.; FREITAS, A. A. F. Propensão empreendedora entre estudantes participantes de empresas juniores. Revista de Empreendedorismo e 
As questões deste instrumento podem ser classificadas em dois grupos: aquelas relacionadas ao perfil comportamental empreendedor, por meio dos construtos supracitados; e outras sócio-acadêmicas, associadas à participação prévia em atividades empreendedoras, tipo de atividades empreendedoras, previsão de abertura de negócios, idade, semestre, sexo e período de permanência em uma Empresa Júnior, sendo esta última pergunta voltada apenas para o estudantes que tiveram a oportunidade de ingressar em uma.

O público alvo da pesquisa foram alunos de graduação em Administração de Empresas de Instituições de Ensino Superior que possuem Empresas Juniores na área de Administração confederadas a Brasil Júnior (Confederação Brasileira de Empresas Juniores). A amostra utilizada foi por conveniência que consiste em uma amostragem não probabilística caracterizada pela facilidade no acesso e "a seleção das unidades amostrais é deixada a cargo do entrevistador" (MALHOTRA, 2006, p. 326). Foram submetidos 200 questionários, sendo 100 para graduandos em Administração de Empresas que já cursaram o primeiro semestre e que não participaram da experiência em Empresa Júnior (não-EJ), e 100 para quem já participou, ou participa.

Para a aplicação dos questionários, realizada em setembro e outubro de 2012, foram utilizadas duas formas: envio de questionários por correio eletrônico e entrega do questionário físico, em sala de aula. Dos questionários submetidos, apenas 75 EEJ (estudantes que participam ou participaram de empresas juniores) foram identificados ainda em fase de graduação, enquanto 100 não-EJ (estudantes que não participaram de empresas juniores) responderam, mas somente 88 questionários foram validados para serem inclusos na etapa de tratamento de dados, totalizando 163 questionários.

Após a tabulação dos dados, foram observadas as médias e desvio padrão para cada variável dos dois grupos com o propósito de constituir uma base de comparação. Para complementar foi realizado o teste de Fisher com objetivo de analisar a significância das diferenças entre as médias das variáveis dos grupos EEJ e não-EJ. Para o tratamento e análise destes dados foi utilizado o software Statistical Package for the Social Sciences (SPSS). 


\section{Análises dos resultados}

Dos 163 respondentes, 78 (48\%) são mulheres e 85 (52\%) são homens (TAB.1), os quais apresentam predominância de idade no extrato acima de 22 até 24 (TAB.2). Os alunos que não participaram de Empresa Junior representam 54\% do total de respondentes com predominância de idade no extrato acima de 22 anos até 24 anos. Já para os 75 alunos que participaram de uma Empresa Júnior (EJ), 39 (52\%) são do sexo masculino e 36 (48\%) são do sexo feminino, com idade predominante no extrato acima de 20 até 22 anos.

De acordo com a Tabela 1, observa-se que a maior concentração de alunos que responderam a pesquisa está entre o quinto e o sexto semestre da graduação. Na categoria dos alunos que não participaram de EJ, há uma maior concentração de alunos no quinto e sexto semestre (27\%) e no nono e décimo semestre (27\%) e uma menor concentração no terceiro e quarto semestre (10\%). Na categoria de alunos que participaram de EJ há uma maior frequência no quinta e sexto semestre (27\%) e menor frequência no nono e décimo semestre (12\%). Uma análise conjunta mostra que a amostra não-EJ apresenta em semestres mais avançados no curso de graduação, bem como com maior idade que os alunos do grupo EEJ.

Tabela 1 - Intervalo de semestres cursados pelos graduandos pesquisados.

\begin{tabular}{|c|c|c|c|c|c|c|}
\hline & \multicolumn{2}{|c|}{ GERAL } & \multicolumn{2}{|c|}{ NÃO-EJ } & \multicolumn{2}{|c|}{ EJ } \\
\hline & Freq. & Perc. & Freq. & Perc. & Freq. & Perc. \\
\hline $\begin{array}{l}\text { entre o } 1^{\circ} \text { e o } 2^{\circ} \\
\text { semestre }\end{array}$ & 24 & $15 \%$ & 10 & $11 \%$ & 14 & $19 \%$ \\
\hline $\begin{array}{l}\text { entre o } 3^{\circ} \text { e o } 4^{\circ} \\
\text { semestre }\end{array}$ & 26 & $16 \%$ & 9 & $10 \%$ & 17 & $23 \%$ \\
\hline $\begin{array}{l}\text { entre o } 5^{\circ} \text { e o } 6^{\circ} \\
\text { semestre }\end{array}$ & 44 & $27 \%$ & 24 & $27 \%$ & 20 & $27 \%$ \\
\hline $\begin{array}{l}\text { entre o } 7^{\circ} \text { e o } 8^{\circ} \\
\text { semestre }\end{array}$ & 36 & $22 \%$ & 21 & $24 \%$ & 15 & $20 \%$ \\
\hline $\begin{array}{l}\text { entre o } 9^{\circ} \text { e o } 10^{\circ} \\
\text { semestre }\end{array}$ & 33 & $20 \%$ & 24 & $27 \%$ & 9 & $12 \%$ \\
\hline Total & 163 & $100 \%$ & 88 & $100 \%$ & 75 & $100 \%$ \\
\hline
\end{tabular}

Fonte: Os autores 
A Tabela 2 apresenta o tempo de permanência dos graduandos que participam ou que participaram de uma EJ. Nesta identifica-se que há uma predominância de graduandos no período de 6 a 12 meses, com 33\%. O tempo de permanência pode ser um fator importante para 0 desenvolvimento de comportamentos relevantes para a formação de empreendedores ou empregados diferenciados. Contudo, a rotatividade é um dos aspectos que pode dificultar o aprendizado e desenvolvimento na Empresa Júnior (VALADÃO JÚNIOR; MARQUES 2012).

Tabela 2 - Intervalo de permanência dos estudantes na Empresa Júnior.

\begin{tabular}{lcc}
\hline & \multicolumn{2}{c}{ EJ } \\
\hline & Freq. & Perc. \\
\hline até 6 meses & 6 & $12 \%$ \\
\hline $\begin{array}{l}\text { acima de } 6 \text { meses até } \\
12 \text { meses }\end{array}$ & 25 & $33 \%$ \\
\hline $\begin{array}{l}\text { acima de } 12 \text { meses até } \\
18 \text { meses }\end{array}$ & 17 & $23 \%$ \\
\hline $\begin{array}{l}\text { acima de } 18 \text { meses até } \\
24 \text { meses }\end{array}$ & 12 & $16 \%$ \\
\hline $\begin{array}{l}\text { acima de } 24 \text { meses até } \\
30 \text { meses }\end{array}$ & 3 & $4 \%$ \\
\hline acima de 30 meses & 9 & $12 \%$ \\
\hline Total & 75 & $100 \%$ \\
\hline
\end{tabular}

Fonte: Os autores

No que diz respeito à educação empreendedora, foi identificado que apenas $13 \%$ dos respondentes não participaram de nenhuma atividade, o que equivale a 22 alunos. Todos eles são do grupo de não participantes de uma Empresa Júnior. De acordo com a Tabela 3, é possível identificar que dos 141 participantes de atividades empreendedoras (não considerando a atividade Empresa Júnior), a maioria presenciou uma atividade prática de abertura de empresas, com frequência de 52 citações (32\%), enquanto apenas 4 pessoas participaram de alguma atividade relacionada à incubadora de empresas. 
Tabela 3 - Números do tipo de atividade empreendedora que os estudantes pesquisados participaram.

\begin{tabular}{ccc}
\hline & \multicolumn{2}{c}{ GERAL } \\
\hline & F. & P. \\
\hline $\begin{array}{c}\text { Elaboração de plano de } \\
\text { negócios }\end{array}$ & 29 & $26 \%$ \\
\hline criação de produto & 22 & $20 \%$ \\
\hline Incubadora & 4 & $6 \%$ \\
\hline Criação de Empresa & 52 & $32 \%$ \\
\hline $\begin{array}{c}\text { Jogos de Empresas e } \\
\text { Simulados }\end{array}$ & 16 & $8 \%$ \\
\hline Outros & 18 & $9 \%$ \\
\hline
\end{tabular}

Fonte: os autores

Em uma primeira leitura da Tabela 4, observa-se que os alunos que participaram de uma Empresa Júnior possuem médias superiores em 19 variáveis referentes ao perfil empreendedor, enquanto os não-EJ apresentaram médias superiores em apenas três variáveis. Segundo Schmidt e Bohnenberger (2009), o item "Meus contatos sociais influenciam muito pouco a minha vida profissional" relacionada à dimensão Sociável possui escala de interpretação reversa, sendo uma das médias em que os alunos que não participaram de EJ apresentaram-se superiores. Portanto, os alunos de EJ apresentaram 20 resultados positivos de variáveis superiores acerca do perfil empreendedor.

Estes resultados apresentam uma tendência identificada em outras pesquisas (LEMOS et al., 2012; VALADÃO JÚNIOR; MARQUES, 2012; VAZQUEZ et al., 2012; BATISTA et al., 2010; FERREIRA et al., 2009; DAL PIVA et al., 2006; FRANCO; FEITOSA, 2006) acerca do aprendizado, desenvolvimento de competências e formação de profissionais diferenciados, por meio da experiência no ambiente de Empresa Júnior. Com os resultados preliminares das médias, observa-se a tendência supracitada para o desenvolvimento de competências empreendedoras, o que, segundo sugere Boyles (2012), torna-se relevante porque o desenvolvimento de comportamentos é uma maneira efetiva de análise do sucesso dos programas de educação empreendedora. 
Contudo, em uma segunda leitura (Tabela 4), considerando o indicador de significância do teste ANOVA (teste F), é possível inferir que há somente seis médias com diferenças significativas (considerando 95\% de confiança).

I. Profissionalmente, me considero uma pessoa muito mais persistente que as demais (item 3);

II. Sempre encontro soluções muito criativas para problemas profissionais com os quais me deparo (item 7).

III. As pessoas respeitam minha opinião (item 8).

IV. Prefiro um trabalho repleto de novidades a uma atividade rotineira (item 12).

V. No trabalho, normalmente influencio a opinião de outras pessoas a respeito de um determinado assunto (item 15).

VI. Conheço várias pessoas que poderiam me auxiliar profissionalmente, caso precisasse (item 18).

No entanto, é importante lembrar que a maioria (87\%) dos estudantes participou de alguma atividade empreendedora, o que pode ser uma justificativa para várias médias relativas ao comportamento empreendedor dos estudantes que não participaram da Empresa Júnior, estarem próximas das médias apresentadas pelos alunos de EJ. 


\section{Tabela 4 - Médias comparativas das manifestações do comportamento}

\section{empreendedor.}

\begin{tabular}{|c|c|c|c|c|c|c|c|}
\hline & \multicolumn{3}{|c|}{ NÃO-EJ } & \multicolumn{3}{|c|}{ EJ } & \multirow{2}{*}{\begin{tabular}{|c|} 
ANOVA \\
SIG. \\
\end{tabular}} \\
\hline & MÉDIA & $\begin{array}{l}\text { DESVIO } \\
\text { PADRÃO }\end{array}$ & $\begin{array}{c}\text { QUESTIONÁ } \\
\text { RIOS }\end{array}$ & MÉDIA & $\begin{array}{l}\text { DESVIO } \\
\text { PADRÃO }\end{array}$ & $\begin{array}{l}\text { QUESTIONÁ } \\
\text { RIOS }\end{array}$ & \\
\hline $\begin{array}{l}1 \text { Frequentemente detecto oportunidades de } \\
\text { negócio no mercado. }\end{array}$ & 4,99 & 1,208 & 88 & 4,91 & 1,535 & 75 & ,704 \\
\hline 2 Tenho um plano da minha vida profissional & 5,22 & 1,360 & 88 & 5,33 & 1,266 & 75 & .571 \\
\hline $\begin{array}{l}3 \text { Profissionalmente, me considero uma pessoa } \\
\text { muito mais persistente que as demais. }\end{array}$ & 5,06 & 1,393 & 88 & 5,52 & 964 & 75 &, 016 \\
\hline $\begin{array}{l}4 \begin{array}{l}\text { Frequentemente as pessoas pedem minha } \\
\text { opinião sobre assuntos de trabalho. }\end{array} \\
\end{array}$ & 5,30 & 1,195 & 88 & 5,32 & 1,153 & 75 & 895 \\
\hline $\begin{array}{l}\text { Creio que tenho uma boa habilidade em } \\
\text { dectectar oportunidades de negócio no mercado. }\end{array}$ & 5,01 & 1,056 & 88 & 5,07 & 977 & 75 & ,731 \\
\hline $\begin{array}{l}6 \begin{array}{l}\text { Frequentemente sou escolhido como líder em } \\
\text { projetos ou atividades profissionais. }\end{array} \\
\end{array}$ & 4,64 & 1,041 & 88 & 4,93 & 1,166 & 75 & 088 \\
\hline $\begin{array}{l}7 \text { Sempre encontro soluções muito criativas para } \\
\text { problemas profissionais com os quais me deparo. }\end{array}$ & 4,84 & 1,082 & 88 & 5,19 & 1,074 & 75 &, 043 \\
\hline 8 As pessoas respeitam minha opinião. & 5,26 & 837 & 88 & 5,61 &, 751 & 75 & 006 \\
\hline $\begin{array}{l}\text { Sempre procuro estudar muito a respeito de cada } \\
9 \text { situação profissional que envolva algum tipo de } \\
\text { risco. }\end{array}$ & 5,40 & 1,237 & 88 & 5,44 & 1,368 & 75 &, 836 \\
\hline $\begin{array}{l}\text { No meu trabalho, sempre planeljo muito bem } \\
\text { tudo oq ue faco. }\end{array}$ & 5,34 & 1,049 & 88 & 5,35 & 1,247 & 75 & ,974 \\
\hline $\begin{array}{l}11 \text { Gosto de mudar minha forma de trabalho } \\
\text { sempre que possivel. }\end{array}$ & 4,65 & 1,398 & 88 & 4,79 & 1,407 & 75 &, 529 \\
\hline $\begin{array}{l}\text { Prefiro um trabalho repleto de novidades a uma } \\
\text { atividade rotineira. }\end{array}$ & 5,14 & 1,315 & 88 & 5,60 & 1,443 & 75 &, 033 \\
\hline $\begin{array}{l}\text { Eu assumiria uma divida de longo prazo, } \\
13 \text { acreditando nas vantagens que uma } \\
\text { oportunidade de negócio me traria. }\end{array}$ & 4,82 & 1,739 & 88 & 5,17 & 1,614 & 75 & ,181 \\
\hline $\begin{array}{l}\text { Meus contatos sociais influenciam muito pouco } \\
\text { a minha profissional. }\end{array}$ & 3,38 & 1,280 & 88 & 3,19 & 1,531 & 75 & ,394 \\
\hline $\begin{array}{l}\text { No trabalho, normalmente influencio a opinião } \\
15 \text { de outras pessoas a respeito de um determinado } \\
\text { assunto. }\end{array}$ & 4,93 & 1,112 & 88 & 5,35 & 1,072 & 75 &, 017 \\
\hline $\begin{array}{l}\text { Os contatos sociais que tenho são muito } \\
\text { importantes para minha vida pessoal. }\end{array}$ & 5,34 & 1,240 & 88 & 5,57 & 1,221 & 75 & ,231 \\
\hline $\begin{array}{l}\text { Tenho controle sobre os fatores para minha } \\
\text { plena realização profissional. }\end{array}$ & 4,64 & 1,008 & 88 & 4,76 & 1,137 & 75 & ,463 \\
\hline $\begin{array}{l}\text { Conheço várias pessoas que me poderiam } \\
\text { auxiliar profissionalmente, caso precisasse. }\end{array}$ & 5,05 & 1,259 & 88 & 5,69 & 944 & 75 & 000 \\
\hline $\begin{array}{l}\text { Me incomoda muito ser pego de surpresa por } \\
\text { fatos que eu poderia ter previsto. }\end{array}$ & 5,60 & 1,109 & 88 & 5,73 & 1,588 & 75 & ,538 \\
\hline $\begin{array}{l}\text { Tenho os assuntos referentes ao trabalho sempre } \\
\text { muito bem planejados. }\end{array}$ & 5,13 & 1,371 & 88 & 5,11 & ,953 & 75 & ,922 \\
\hline $\begin{array}{l}\text { Me relaciono muito facilmente com outras } \\
\text { pessoas. }\end{array}$ & 5,40 & 1,344 & 88 & 5,56 & 1,328 & 75 & ,441 \\
\hline $\begin{array}{l}22 \\
\text { Admito correr riscos em troca de possiveis } \\
\text { beneficios. }\end{array}$ & 4,89 & 1,139 & 88 & 5,13 & 1,563 & 75 & ,246 \\
\hline
\end{tabular}

Fonte: Os autores

FERREIRA, E. R. A.; FREITAS, A. A. F. Propensão empreendedora entre estudantes participantes de empresas juniores. Revista de Empreendedorismo e 
Cada um dos itens com diferença significativa são interessantes de serem explorados. O item três, inicialmente, é uma manifestação do construto autorealização, formado pelos elementos: persistência, auto-eficácia e detecção de oportunidades. De acordo com a Tabela 4, os estudantes que não passaram por EJ apresentam média 5,06. Já os estudantes que participaram de uma EJ obtiveram média de 5,52 para o indicador relacionado à persistência profissional. Este achado pode ser atribuído aos desafios e riscos que o ambiente de Empresa Júnior propõe, por meio da interação com clientes e outros estudantes e decisões que podem impactar no futuro da EJ (VAZQUEZ et al., 2012).

No item 12, que é um indicador do construto Inovação, os alunos que participaram de EJ apresentaram média de 5,60, enquanto os alunos que não participaram de uma EJ apresentaram 5,14. Uma explicação para este resultado é a autonomia de trabalho que os Empresários Juniores possuem em seu dia-a-dia, bem como o trabalho concentrado, geralmente, mais em projetos do que em processos atividades rotineiras. A oportunidade de interagir com situações novas é uma característica das EJs valorizada pelos seus componentes: "os jovens são descritos como ansiosos por novidades, desafios e pouco tolerantes ao cotidiano e procedimentos sempre iguais e rotineiros" (LEMOS, et al. 2012, p. 99).

O item 15 denominado pela afirmativa "no trabalho, normalmente influencio a opinião de outras pessoas a respeito de um determinado assunto" e relacionada ao construto Assume Riscos obteve média de 5,35 nos alunos de EJ, enquanto que, nos outros alunos, a média obtida foi de 4,93. Estas médias podem ser resultantes de uma característica semelhante entre as Empresas Juniores que é o poder de opinião que os jovens participantes possuem, pois são eles que formam e gerenciam estas organizações.

A mesma explicação que justifica o resultado do item 15 pode ser utilizada para a item8 que está relacionada ao construto Líder. Este item apresentou média de 5,26 para não participantes de EJ e 5,61 para os que fazem ou fizeram parte de uma. Este achado está de acordo com os resultados de outros estudos que apresentam o desenvolvimento do espírito de liderança, por meio da experiência em EJ (VALADÃO JÚNIOR et al., 2012; DAL PIVA et al., 2006). 
Observa-se também significativa diferença entre as médias do item 18 que é uma manifestação do construto Sociável. Os alunos de EJ obtiveram média de 5,69, enquanto os outros alunos obtiveram média de 5,05. O resultado desta variável pode ser uma resultante da interação social obtida na experiência de gerenciamento de um negócio, relacionamento com outros membros participantes, clientes e parceiros. Ressalta-se ainda que os Empresários Juniores participam de eventos em formato de imersão, momento em que é incentivada a troca de práticas de sucesso entre empresas juniores, o que contribui para a formação de uma rede de contatos em todo o país. Estes momentos são de grande relevância, pois incentivam a troca de ideias e reflexão em grupo, o que são fatores relevantes de aprendizado, nos programas de educação empreendedora (ELMUTI et al. 2012; BARGHERI, PIHIE, 2009), e que contribuem para o desenvolvimento de características do construto Sociável.

Por fim, a última média que apresentou diferença significativa foi proveniente do item 7, do construto Auto-realização. A média identificada para os alunos de EJ foram de 5,19, enquanto que, para os alunos que não participaram, apenas 4,84. Este resultado está alinhado com o achado na pesquisa de Lemos et al. (2012) e, de acordo com Batista et al. (2010, p. 15), apesar da inexperiência dos jovens Empresários Juniores, "eles apresentam grande vontade e determinação para atingir seus objetivos que, na maioria das vezes, se expressam através da busca de conhecimentos (...)".

No que diz respeito à abertura de um novo negócio, os dados contidos na Tabela 5 mostram que 42 alunos não pretendem abrir um negócio, enquanto 121 alunos planejam iniciar um. Há uma maior propensão dos alunos abrirem após 5 anos de formados (33\%). Em uma leitura mais específica, observa-se que os alunos que não participaram de EJ apresentam uma intenção inferior de abrir um negócio, de apenas 68\%, quando comparado aos alunos de EJ, de 88\%. Portanto, é possível observar que a maioria dos graduandos pesquisados, os quais $87 \%$ participaram de algum programa de educação empreendedora, apresentam interesse em iniciar um negócio, o que está de acordo com os objetivos destes programas.

Por outro lado, visualiza-se que os alunos de EJ planejam abrir um negócio em um prazo superior aos alunos nao-EJ. Uma possível explicação para este 
achado é que, ao viver a experiência de gerenciar uma empresa, os alunos presenciam as dificuldades e os riscos que um negócio gera, contribuindo para uma maior prudência por parte destes, que passam a almejar ter mais experiência para iniciar um. Ressalta-se ainda que, no estudo conduzido por Ferreira et al. (2009), apenas 4 pesquisados, dos 44 , iniciaram a carreira com um negócio próprio.

Tabela 5 - Previsão de abertura de um negócio após a graduação.

\begin{tabular}{ccc|cc|cc}
\hline & \multicolumn{2}{c|}{ GERAL } & \multicolumn{2}{c|}{ NÃO-EJ } & \multicolumn{2}{c}{ EJ } \\
\hline & Freq. & Porc. & Freq. & Porc. & Freq. & Porc. \\
\hline $\begin{array}{c}\text { Pretendo abrir um negócio } \\
\text { entre 1 e 2 anos, após minha } \\
\text { graduação. }\end{array}$ & 29 & $18 \%$ & 17 & $19 \%$ & 12 & $16 \%$ \\
\hline $\begin{array}{c}\text { Pretendo arir um negócio } \\
\text { entre 3 e 5 anos, após minha } \\
\text { graduação. }\end{array}$ & 38 & $23 \%$ & 20 & $23 \%$ & 18 & $24 \%$ \\
\hline $\begin{array}{c}\text { Pretendo abrir um negócio } \\
\text { após 5 anos de graduado. }\end{array}$ & 54 & $33 \%$ & 23 & $26 \%$ & 31 & $41 \%$ \\
\hline $\begin{array}{c}\text { Não pretendo abrir um } \\
\text { negócio após a minha } \\
\text { graduação. }\end{array}$ & 42 & $26 \%$ & 28 & $32 \%$ & 14 & $19 \%$ \\
\hline$\quad$ Total & $\mathbf{1 6 3}$ & $\mathbf{1 0 0} \%$ & $\mathbf{8 8}$ & $\mathbf{1 0 0 \%}$ & $\mathbf{7 5}$ & $\mathbf{1 0 0 \%}$ \\
\hline
\end{tabular}

Fonte: Os autores

Na seção seguinte serão relatadas as considerações finais do estudo.

\section{Considerações finais}

Compreendendo o crescimento do número de Empresas Juniores em nosso país, a busca dos graduandos pelo engajamento nestas organizações e o discurso de que esta experiência contribui para a formação de profissionais diferenciados, o propósito deste estudo foi identificar se esta experiência que, de acordo com os seus propósitos, objetiva a formação de empreendedores, realmente é eficaz neste intuito.

Conforme identificado na pesquisa, constatou-se pelo quantitativo das médias que os membros e ex-membros de EJ apresentaram 20 variáveis do comportamento empreendedor superior aos que não tiveram a mesma oportunidade, evidenciando um contributo expressivo na formação profissional dos seus componentes. Esse 
contributo está relacionado principalmente a características sociais que apenas com a teoria vista em sala de aula não seria possível desenvolvê-las.

É necessário destacar que, apesar dos não participantes de Empresa Júnior estarem mais avançados no curso de Administração de Empresas e a maioria ter participado de outros programas de educação empreendedora, os resultados demonstraram que os alunos que participam ou participaram de uma Empresa Júnior apresentaram comportamentos empreendedores significativamente mais expressivos, quando comparados com os alunos que não participaram de uma Empresa Júnior. Em outras palavras, observa-se que os alunos que participam de EJ possuem mais manifestações do comportamento empreendedor, dos que os alunos que não participaram de uma Empresa Júnior.

Outro achado significativo identificado é que os alunos que participam ou participaram de uma Empresa Júnior apresentam maior interesse em abrir um negócio do que os alunos que não participaram. Entretanto, os alunos não-EJ que pretendem iniciar um negócio tendem a começar mais cedo, quando comparado com os alunos de EJ.

Como limitação é preciso reconhecer a natureza da amostra não probabilística, que não permite gerenalização dos resultados e a impossibilidade de fazer cálculos sobre a confiabilidade da amostra em função do tamanho da população. No entanto, é possível inferir que a experiência em Empresa Júnior é um programa educacional que contribui para a formação empreendedora dos estudantes que participam, por meio do desenvolvimento de atitudes empreendedoras e do interesse identificado nesta pesquisa em iniciar um negócio, mesmo sendo a longo prazo.

Um fator que pode ser melhor explorado é quanto ao curso de graduação dos componentes de uma Empresa Júnior. Neste estudo, a amostra atentou-se apenas a estudantes de Administração de Empresas, o que impossibilita uma inferência generalizada para EJs. Portanto, sugere-se que em próximos estudos seja levado em consideração: (I) o tempo de existência da Empresa Júnior por ser um fator de consistência dos mecanismos de gestão da EJ; (II) a área do conhecimento que a EJ está inserida - Humanas, Ciências Sociais Aplicadas, Exatas; e (III) o tempo de permanência médio dos componentes, sendo definido um valor mínimo para 
participação de pesquisas aquele que a Brasil Júnior considera como excelente nos seus mecanismos de avaliação de uma EJ.

Por fim, este estudo atentou-se apenas a estudantes, não sendo possível identificar se de fato os ex-membros de EJ que já se formaram realmente iniciaram um negócio. Mas, de acordo com o que foi evidenciado nesta pesquisa, é possível inferir que a experiência neste "laboratório" é uma oportunidade de desenvolvimento de características profissionais relevantes que serão aproveitadas independente da carreira que o estudante optar. Isto sugere uma reflexão no modelo de educação que vem sendo adotado em diversas instituições de ensino e que ainda está muito distante da prática e do desenvolvimento que tal experiência pode gerar no estudante.

\section{Referências:}

ÁCS, Z. How is Entrepreneurship Good for Economic Growth? In: ECONOMIC CONFERENCE OF PROGRESS FOUNDATION, 31, 2007. Disponível em: http://www.progressfoundation.ch/PDF/referate/185 Lecture\%20Zoltan\%20J.\%20Ac s\%2031.10.07.pdf. Acessado em: 06.10.2012

BAGHERI, A; PIHIE, Z. A. L. An Exploratory Study of Entrepreneurial Leadership Development of University Students. European Journal of Social Sciences, v. 11, n. 1, p. 177-190, 2009.

BATISTA, M. K; BITENCOURT, B. M; MOLON DA SILVA, F; RUAS, R. L. Empresa Júnior: onde a moeda de troca é o conhecimento. In: ENCONTRO NACIONAL DOS PROGRAMAS DE PÓS-GRADUACCÃO EM ADMINISTRAÇÃO, 34, 2010, Rio de Janeiro. Anais. Rio de Janeiro: ANPAD, 2010.

BAUMOL, W. J. Formal Entrepreneurship Theory in Economics: Existence and Bounds. Journal of Business Venturing, v. 8, p. 197-210, 1993.

BOYLES, T. 21st Century Knowledge, Skills, and Abilities and Entrepreneurial Competencies: A Model For Undergraduate Entrepreneurship Education. Journal of Entrepreneurship Education, v. 15, p. 41-55, 2012.

BRASIL JR. Conceito Nacional de Empresa Júnior - 2009. Sistema Brasil Jr Arquivos. Disponível em: http://brasiljunior.org.br/site/arquivos Acesso em: 2 out. 2012. 
BRASIL JR. DNA Jr Empresa Júnior. Sistema Brasil Jr - 2008 - Arquivos. Disponível em: http://brasiljunior.org.br/site/arquivos Acesso em: 2 out. 2012.

BRASIL JÚNIOR. Relatório Nacional Censo e Identidade 2010. Sistema Brasil Jr 2011 - Arquivos. Disponível em: http://brasiljunior.org.br/site/arquivos Acesso em: 2 out. 2012.

BRASIL JÚNIOR, Relatório Nacional Censo e Identidade 2011. Sistema Brasil Jr. 2012 - Arquivos. Disponível em: http://brasiljunior.org.br/site/arquivos Acesso em: 2 out. 2012.

BYGRAVE, W. D. The entrepreneurial process. In: W.D. BYGRAVE AND A. ZACHARAKIS (EDS.), The Portable MBA in Entrepreneurship, 3rd ed, New York: John Wiley and Sons, 2003.

CARMO; R. M.; NASSIF, V. M. J. Incubadoras de empresas e a capacidade empreendedora das pessoas. In: ENCONTRO NACIONAL DA ASSOCIAÇÃO NACIONAL DE PÓSGRADUAÇÃO E PESQUISA EM ADMINISTRAÇÃO, 29, 2005, Brasília. Anais... Brasília: ANPAD, 2005.

CHEUNG, Chi-Kim; AU, E. Running a small business by students in a secondary school: its impact on learning about entrepreneurship. Journal of Entrepreneurship Education, v. 13, p. 45-63, 2010.

CORNELIUS, B; LANDSTRÖM, H; PERSSON, O. Entrepreneurial studies: the dynamic research front of a developing social science. Entrepreneurship Theory and Practice, p. 375-398, May, 2006.

DAL PIVA, A. R; PILATTI, L. A; FERRAZZA, D. C; SILVA, E. Empresa júnior: um laboratório de aprendizagem como diferencial para a formação acadêmica. In: XIII SIMPÓSIO DE ENGENHARIA DE PRODUÇÃO, 11, 2006, Bauru. Anais... Bauru, 2006.

DANTAS, E. B. Empreendedorismo e intra-empreendedorismo: é preciso voar com os pés no chão, 2008. Disponível em: http://www.bocc.ubi.pt/pag/dantas-edmundoempreendedorismo.pdf Acessado em: 12 out. 2012.

ELMUTI, D; KHOURY, G; OMRAN, O. Does entrepreneurship education have a role in developing entrepreneurial skills and ventures' effectiveness? Journal of Entrepreneurship Education, v. 15, p. 83-98, 2012.

EUROPEAN COMMISSION (2012). Effects and impact of entrepreneurship programmes in higher education. Disponível em: http://brasiljunior.org.br/site/arquivos/download/16 Acesso em: 02 out. 2012.

FERREIRA, A. S; FONSECA, L; SANTOS, L. Serão os 'estudantes empreendedores' os empreendedores do futuro? O contributo das empresas 
juniores para o empreendedorismo. Faculdade de Economia do Porto Working Papers, n. 333, 2009.

FILARDI, F; SILVEIRA, F. A; CAPRA, L. P; PEREIRA, L. S; ABREU, M. A. S. S. Desde os primórdios até hoje em dia será que o empreendedor ainda faz o que schumpeter dizia? evolução das características empreendedoras de 1983 a 2010. In: ENCONTRO NACIONAL DOS PROGRAMAS DE PÓS-GRADUAÇÃO EM ADMINISTRAÇÃO, 35, 2011, Rio de Janeiro. Anais... Rio de Janeiro: ANPAD, 2011.

FILION, L. J. Empreendedorismo: empreendedores e proprietários-gerentes de pequenos negócios. Revista de Administração, v. 34, n. 2, p. 05-28, 1999.

FILION, L. J. O Empreendedorismo como tema de estudos superiores. In: DOLABELA, F. et al. Empreendedorismo: Ciência, Técnica e Arte. Brasília: CNI/IEL Nacional, 2000.

FILION, L.J. From entrepreneurship to entreprenology. In USASBE ANNUAL NATIONAL CONFERENCE ENTREPRENEURSHIP. 1997, São Francisco. Anais... São Francisco, 1997.

FILION, L.J. Defining the Entrepreneur. complexity and multi-dimensional systems.some reflections. In: DANA, L. P. (Ed) WORLD ENCYCLOPEDIA OF ENTREPRENEURSHIP. Cheltenham, UK and Northampton, MA, USA, Edward Elgar, $\quad$ p. 41-52, 2011. 2 Disponível em; http://expertise.hec.ca/chair entrepreneurship/wp-content/uploads/2008-03-Definingthe-Entrepreneur-Complexity-and-Multi-Dimensional-Systems-Some-Reflections.pdf Acesso em 21 de set. 2012.

FRANCO, A. P.; FEITOSA, M. G. G.;. Da sala de aula ao mundo empresarial: compreendendo a aprendizagem dos consultores juniores em suas relações com 0 sistema-cliente. In: ENCONTRO NACIONAL DOS PROGRAMAS DE PÓSGRADUAÇÃO EM ADMINISTRAÇÃO, 30, 2006, Salvador. Anais... Salvador: ANPAD, 2006.

GEM - GLOBAL ENTREPRENEURSHIP MONITOR. Empreendedorismo no Brasil: 2007 / Carlos Artur Krüger Passos et al. Curitiba: IBQP, 2008

GEM - GLOBAL ENTREPRENEURSHIP MONITOR. Empreendedorismo no Brasil - Pesquisa Completa. IBQP, SEBRAE, SENAI, SESI, UFPR. Curitiba: 2010.

GEM - GLOBAL ENTREPRENEURSHIP MONITOR. Empreendedorismo no Brasil Resumido, 2002. Disponível em: http://www.gemconsortium.org/docs/download/438. Acesso em: 10 set. 2012.

HOJJATI, S. M. H.. How entrepreneurs influence the success of developing countries. Business Management Dynamics, v. 1, n. 11, p. 63-67, 2012. 
KURATKO, D. F. A tribute to 50 years of excellence in entrepreneurship and small business. Journal of Small Business Management, v. 44, n. 3, p. 483-492, 2006.

KURATKO, D. F. The emergence of entrepreneurship education: development, trends, and challenges. Entrepreneurship Theory And Practice, p. 577-597, set, 2005.

LEMOS, A. H. C.; COSTA, A. M.; VIANA, M. D. A.;. Empregabilidade e inserção profissional: expectativas e valores dos participantes de empresas juniores. Revista do Pensamento Contemporâneo em Administração, v. 6, n. 1, p. 91-104, 2012.

MALHOTRA, N. K. Pesquisa de marketing: uma orientação aplicada, 4 Ed Porto Alegre: Bookman, 2006.

MURPHY, P. J; LIAO, J; WELSH, H. P. A conceptual history of entrepreneurial thought. Journal of Management History, v. 12, n. 1, p. 12-35, 2006.

RAMAYAH, T.; AHMAD, N. H; FEI, T. H. C. Entrepreneur education: does prior experience matter? Journal of Entrepreneurship Education, v. 15, p. 65-81, 2012.

SAES, D. X; PITA, F. H. S. Empreendedorismo no ensino superior: uma abordagem teórica. Maringá Management: Revista de Ciências Empresariais, v. 4, n. 2, p. 3341, 2007.

SCHIMDT, S; BOHNENBERGER, M. C. Perfil empreendedor e desempenho organizacional. Revista de Administração Contemporânea, v. 13, n. 3, p. 459-467, 2009.

SOUZA, C. P. S; LIMA, L. L. B; MARQUES, A. A. Fatores condicionantes da motivação de colaboradores voluntários: estudo de caso de uma empresa júnior da Universidade Federal de Alagoas. In: ENCONTRO NACIONAL DOS PROGRAMAS DE PÓS-GRADUAÇÃO EM ADMINISTRAÇÃO, 32, 2008, Rio de Janeiro. Anais... Rio de Janeiro: ANPAD, 2008.

STEVENSON, H. H; JARILLO, J. C. A Paradigm of entrepreneurship: entrepreneurship management. Strategic Management Journal, v. 11, p. 17-27, 1990.

VALADÃO JÚNIOR, V. M; MARQUES, R. A. C. Empresa júnior: espaço para construção de competências. In: ENCONTRO NACIONAL DOS PROGRAMAS DE PÓS-GRADUAÇÃO EM ADMINISTRAÇÃO, 36, 2012, Rio de Janeiro. Anais... Rio de Janeiro: ANPAD, 2012.

VAZQUEZ, A, C. S; MOLON DA SILVA, F; NATIVIDADE, J. C; RUAS, R. L. Aprendizagem em situações práticas: a formação profissional na experiência de alunos em empresas juniores no Brasil. In: ENCONTRO NACIONAL DOS

FERREIRA, E. R. A.; FREITAS, A. A. F. Propensão empreendedora entre estudantes participantes de empresas juniores. Revista de Empreendedorismo e 


\section{REVISTA}

PROGRAMAS DE PÓS-GRADUAÇÃO EM ADMINISTRAÇÃO, 36, 2012, Rio de Janeiro. Anais... Rio de Janeito: ANPAD, 2012.

Artigo recebido em:22/07/2014. Aprovado em:23/09/2013 